\title{
History of Childhood Oppression, Inter-Temporal Resentment and Compliance with Codes of Harassment at the Workplace: An Offender's Perspective
}

http://doi.org/10.21272/bel.3(4).6-14.2019

Syed Toqueer Akhter, ORCID: https://orcid.org/0000-0002-1474-4954

MSc, Consultant and Freelance Researcher, Olso, Norway

Humna Butt, ORCID: https://orcid.org/0000-0002-1171-2826

MSc, Transfer Pricing Associate at Deloitte, Dubai, UAE

\begin{abstract}
This study tends to identify intents and inclinations that explain low/ high compliance with the codes of provocation/harassment, at the workplace. Despite the reason and the fact that most literature on the subject takes into account the perspective of victims of harassment at workplace, this study prefers to take crosssectional basis of the offender's perspective. Studies on matters of harassment are generally prone to potential syndromes such as 'accuse the victim' and deliberation by state institutions in under-reporting of crime. Victims of sexual harassment, in most of the cases, don't tend to share such sensitive information, instantaneously. Generally, past happenings of provocation and harassment are not been disclosed for decades, may be due to 'social desirability bias' or due to apprehension of losing job/career, as in most of such cases some senior fellow at the workplace is found involved in such provocation. An in-depth and detailed questionnaire with several sections has been furnished and floated primarily among male counterparts at the workplace, in Pakistan. In order to acquire responses with minimal biases, a counter biasing statement was included as part of the interview, while respondents were deemed assured that their identity and responses won't be revealed to any other person or institution. In order to be cautious and prudent about the credibility of the proposed study and in ensuring concurrent validity of the analysis, three competing models: Ordered Logit; Ordered Probit; and Robust regression have been estimated. Estimated models, consistently suggested: positive and significant impact of strong neighbourhood effect upon intent of provocation; positive and strong impact of personality trait jealousy; high and significant intent of provocation by persons with high exposure to abuse in form of witnessing or experiencing; while the most interesting finding is that persons with a strong history of abuse in their childhood, especially by their close relatives, develop resentment overtime against provocations, and have high compliance with codes of sexual harassment.
\end{abstract}

Keywords: Sexual harassment, Childhood provocation, Chronic fatigue syndrome, Inter-temporal, Orderedlogit, Ordered-probit, Robust regression.

JEL Classification: J13, J16, C21.

Cite as: Akhter, S. T., Humna, B. (2019). History of Childhood Oppression, Inter-Temporal Resentment and Compliance with Codes of Harassment at the Workplace: An Offender's Perspective. Business Ethics and Leadership, 3(4), 6-14. http://doi.org/10.21272/bel.3(4).6-14.2019.

(C) The Authors, 2019. This article is published with open access at Sumy State University.

\section{Introduction}

Women in Pakistan generally are seen as deprived and oppressed: they have restrained outreach to civic rights; they are discriminated and humiliated in forms of household disempowerment and domestic violence; they are more prone to maltreatment and provocation at the workplace; last but not the least, they have limited access to the legal enforcement and protectionist's framework. One form of vulnerability leads to another, while intergenerational transfusion of repression has led to accumulation of induced vulnerabilities: caused added complexity in holding of analysis as well as with regards to policy formation, in dealing with the crisis of maltreatment, provocation and sexual harassment (Amir, Fatima \& Aziz, 2018; Channar, Abbassi \& Ujan, 2011). 
Though the history of provocation/harassment at the workplace has old traces, the topic gained the attention of academicians due to the structural transformation of societies and economies. Rapid change has been witnessed in the form of transition from primitive societies to the phase of industrialization, and then towards deindustrialization in the last couple of decades, internationally. In traditional societies activities such as farming, hunting and cattle had a predominant share in routine livelihood, so women at the workplace were used to experience some degree of protectionism, as they were used to work with their own family members: brothers, father or with husband. Since, females with relatively low educational profiles start participation in manufacturing and then in services sectors, sizable cases of harassment at the workplace were witnessed. Civil society movements such as feminism, gender equity, female protectionism and gender neutrality, further sensitized the need to deep probe into issues of harassment.

\section{Empirics, Data Mining and Research Concerns}

Pakistan is a patriarchal society with low levels of female participation rates in the labor force, ranging around only $30 \%$, which implies low comparative rating of Pakistan in comparison with South Asian countries, or even with Muslim countries (Piler, 2007). High fear of maltreatment as well as due to apprehensions of harassment at the workplace, females in their age of career development, either prefer to stay at home, they are being restrained by family members to go out for their livelihood, or parents tend to agree for their early marriages. Any news or the information about the incidence of provocation travels in close societies through the 'word of mouth', causing induced vulnerabilities for victims both at home and at the workplace. To avoid the trauma of harassment and its later consequences in form of the high opportunity cost (explicit humiliation and induced vulnerabilities being faced by victims, overtime), family members may restrict or compel their females to participate in the labor force: commonly known as cultural and religious constraints/bottlenecks, been posed by society.

According to World Economic forum's 'Global Gender gap Report, 2018', Pakistan ranked $148^{\text {th }}$ out of 149 surveyed countries in 2018; ranked $146^{\text {th }}$ according to economic participation of females; ranked $139^{\text {th }}$ according to educational outreach \& attainment of females; $145^{\text {th }}$ in health \& survival conditions of females, while is also ranked low among nations concerning the' Gender Empowerment Measure'(GEM) (World Economic Forum, 2018).

Hegemonic masculinity has multifaceted and deep roots in socio-cultural norms in Pakistan: from perceived patriarchy to male supremacy in gender relations, that cause behaviours such as domestic violence, intimate partner violence (IPV) to high inclination of maltreatment and harassment at the workplace (Critelli, 2010; Zakar, Zakar \& Kroemer, 2013). Women from all socio-economic segments of society, despite positionality and occupational belonging, face a varying degree of provocation or harassment, in Pakistan (HIES, 2017; Shaikh, 2016; Rafi, Fatima \& Aziz, 2018). Data issued by Guttmacher Institute in 2015 for Pakistan, reveal that around $40 \%$ of pregnancies were unintended, while the rate of induced abortions ranged around $25 \%$. Despite having agreement/ disagreement with these estimates, the situation remains bleak as maltreatment and provocation of females both at home and at the workplace remain a social norm. Sometimes, the behaviour of parents in form of arranging early marriages of their daughters, imply their inability in providing protection to their daughters or it may be termed as the risk aversion behaviour: refraining from the trauma of harassment. Pakistan is ranked 6 amongst countries with high rates of marriages, before the age of 18 years.

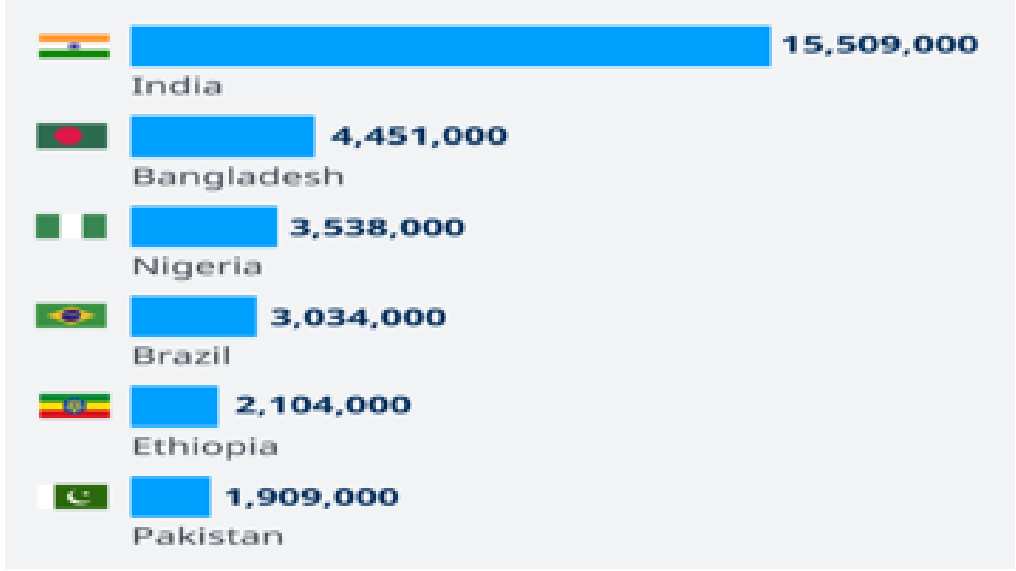

Figure 1. Countries with the highest number of child marriages

Source: United Nations data on 'Women who were first married or in a union before they were 18-years old'. Courtesy DW 
ISSN (online) - 2520-6311; ISSN (print) - 2520-6761

Several theoretical explanations and interpretations have emerged, time to time in literature of harassment \& provocation: role approaches and intimate role expectations, especially when not been institutionalized through protectionism cause higher the risk of noncompliance with codes of harassment (Gutek \& Morasch, 1982); sizable gaps in social and economic positionality between men and women may lead to repression and maltreatment of females at the workplace (Hemming, 1985; Ridgeway \& England, 2007); Imbalances of gender ratios and gender roles in context of organizational demographics cause weak resentment against intent of harassment (Fain and Anderson, 1987); history of childhood abuse creeps over the span of life as people who are being victimized in their childhood, remain vulnerable to exploitation, victimization and to the extent of sexual maltreatment in their adulthood (Gagné, Lavoie \& Hébert, 2005); and last but not the least the female occupational engagement and diversity led to increased gender interaction, hence causing greater the risk of harassment (Gutek, Cohen, \& Konard, 1990).

Overall, weak compliance, sizable and increasing instances of harassment at the workplace, not just implies limited success of protectionist policies but also the need to revisit the researcher's analytical depth in dealing with the issue (Sangwan \& Thakre, 2018). In this study, we plan to trace the interconnectivity of intent of harassment with personality traits of the offender, with the history of childhood provocation of the offender, the impact of neighborhood effect, etc. Little literature takes the perspective of the offender, as most literature is highly inclined towards the perspective of the victim.

\section{Evolution of Legislative Reforms}

Maltreatment, provocation and matters of harassment, as a legal crime had gained considerable attention since the formation of Alliance against Sexual Harassment AASHA, in 2001 (Parveen, 2010; Mahmood \& Ahmad, 2011). Later it got authorities in Pakistan to consent to begin taking a shot at an arrangement structure, which could turn into a hostile to harassment approach for the nation. In 2002, AASHA together with the Government of Pakistan began chipping away at building up an approach casing work and working nearly with the ILO and senior Government authorities to address the issue of sexual harassment. This arrangement was called the Code of Conduct for Gender Justice. AASHA later acquainted the arrangement with the private sector with the understanding of the Government. Analyzing the efforts, it is observed that it must have contributed to the awareness of harassment as social negative externality phenomena, which needed to be addressed in order to provide an environment that secured freedom of workers. AASHA's endeavors brought about the reception of the Code by many private sector companies. After understanding the change in the atmosphere of those associations where the Code was presented, furthermore the increment in the incitement of female employees, AASHA chose to backtrack to the Government for asking for a legitimate spread for the Code of Conduct for Gender Justice. To further act as a catalyst, parliament passed a bill to further alter the Pakistan Penal Code 1860 and the Code of Criminal Procedure 1898, but it received negative feedback from religious parties. In 2010, the Protection against Harassment of Women at Workplace Bill came into force. Since then not only awareness about harassment issues has improved but the number of complaints has also increased, significantly. Some interpret it as a positive development as a greater proportion of violation of codes is being reported now, while there are serious apprehensions that legislative structure and the implementation mechanisms have very limited success (Sangwan \& Thakre, 2018).

Operationalization of codes of sexual harassment and the needed legislative structure of reforms are in a phase of transition, worldwide. In most cases, domain \& diversity of harassment in the form of direct provocation/assault, verbal expression or in the form of gestures require the definitions to be adapted according to socio-cultural heritage in a country. For instance, greeting expressions in some Latin American countries involve a bit of physical contact, while such gestures may be taken as a violation of socio-cultural norms in Muslim countries. In multicultural and outward-looking societies, due to social and cultural globalization, it may be tricky to create a line of distinction among low/ high intensity of harassment, as the punishment of such offense is highly conditional upon the severity of the act. In societies with high cultural absorption capacity, people find their own ways to deal with such happenings without involving state institutions in reporting of an instance of harassment. If any such instance is being reported, it is always been critical to determine, which evidence is seen as creditable: proclaimed humiliation of the victim or the evidence, which is verifiable by other means?

Some of the previous researches on Pakistan discuss the frequency of harassment faced by women at workplaces and its effects on the women (Mahmood \& Ahmad, 2011; Amir, Fatima \& Aziz, 2018); sexual harassment faced by junior student medical and academic staff (Qureshi et al., 2012; Naveed, Tharani \& Alwani, 2010); the domain and diversity of the intent of violence is not just confined to workplace harassment, even it ranges to Intimate Partner Violence with increased intensity (Zakar et al., 2013); and last but not the least on perceptions of sexual harassment and attitudes of women at the workplace (Mahmood \& 
Ahmad, 2011). Despite the high usefulness of initial studies on Pakistan, most studies neither incorporated the offender's perspective nor did they estimate the strength of the relationship between causative factors and the intent of compliance/ noncompliance.

\section{Literature Review}

Research has shown discrimination at the work manages to be an obstacle for gender parity (Olson \& Brian, 1983; Channar, Abbassi \& Ujan, 2011). It considers men as a predominant gimmick, effective, free and prevalent identity of the general public, women, on the other hand, are considered to be mere male belongings; powerless, weak along with subordinated characters of men. Through this attitude, men are looked up as dependable and responsible for the entire family, including the female. The main reasons for gender discrimination are mostly ingrained in the culture and then relates to organizational structures (Ridgeway and England, 2007). Apparent disagreeableness of conduct was emphatically identified with the probability that exploited people would not report sexual harassment (Creeks and Perot, 1991). This unreported demonstration generally persuades the wrongdoer to proceed with hostile conduct (Hamlin \& Hoffman, 2002).

Provocation and unanticipated use of drugs has a relationship between harassment and drug abuse, results were mostly intervened by trouble (Richman J.A. et al., 2001). Almost 66\% of the offenders suffer from substance abuse in some way or another (Boland, Henderson \& Baker, 1998). However, a reconsideration of some prior information gathered uncovered that half of the sexual guilty parties were inebriated at the time of their late offense (Marshall, Bryce, Hudson \& Moth, 1996). Langevin and Lang (1990) also did a research experiment testing all the sexual offenders for drug/alcohol abuse. The results showed that more than 50\% of the sample size suffered from alcohol misuse while $20 \%$ suffered from drug abuse. McGue, Slutske, and Lacono (1999) observed that the consumption of alcohol was associated with emotional imbalances and lack of restraint. When observed the effects of drug abuse only it was seen that most of them suffered from emotional imbalances. The research has been further attested by Abbey et al. (1998) whose research also found that $47 \%$ of the respondents in a college survey who confessed for sexual harassment were drunk at that moment.

Though, most of the literature discussing the impact of childhood oppression suggests that it might lead to low compliance with codes of sexual harassment, without differentiating or classifying the source of the childhood oppression: Blood relatives or far relatives. But we have a strong notion that as far as victims are concerned, they may show low resistance or resentment to any attempts of provocation but as far as offender's perspective is concerned, we tend to believe that persons with the history of childhood oppression by blood relatives, create extraordinary hatred against such humiliation and this sentiment urges resentment over time, so while committing any offense such people are low contributors to harassment initiatives. As soon as the positionality of an oppressed child changes over time he tends to distance himself from provocation in anticipation of earning disrespect from others. Most of the personalities are one shaded: either victim or offender. A victim may not be an offender, soon. Briere \& Runtz (1987) believed that background marked by child abuse has been connected with non-compliance with the codes of harassment and also physical mistreatment, in spite of its relatively early stages, child abuse examination has given generous material on the mental aspect of sexual harassment. The commitment of family elements to this crime of harassment has gotten extensive consideration in later times; that is, family elements assume an imperative part in advancement in addition to the upkeep of adolescence committing a crime (Salmelainen, 1995 \& 1996; Cullingford \& Morrison, 1997). Therefore, it is deduced so as to the controversy that a significant part of the origin of harassment lays inside the family home.

Earlier research shows that an extensive variety of mental and interpersonal issues are more common among the individuals who have been sexually misused in their childhood than among people with no such encounters. Albeit a complete cause and effect, the relationship between such troubles and childhood abuse can't be determined but after reviewing research approaches, the total of steady discoveries in this writing has driven numerous to presume that adolescence abuse is a noteworthy danger element for a mixed bag of issues. The different issues and manifestations depicted in the writing on child abuse are explored in a progression of general classes including posttraumatic anxiety, cognitive mutilations, torment, shirking, and a feeling of self and interpersonal challenges. Investigations have exhibited that the degree to which a given individual shows abuse-related trouble is a capacity of an undetermined number of abuse-particular variables, and also individual and ecological elements that existed before, or happened ensuing the episodes of childhood abuse. 
ISSN (online) - 2520-6311; ISSN (print) - 2520-6761

Regardless, by essentially showing the purposes behind resistance with codes of harassment in regard to child abuse tends to massively distort the multifaceted mental and societal strategies, which direct the youthful towards offending (Venter et al., 2017). Moreover, sub-variables of child abuse likewise add to the affront. These include child-rearing conduct and technique, including the level of parental supervision, parental dismissal and guardian reaction to kid's requirements; financial as well as public anxiety emerging from joblessness, neediness also sole child-rearing; family brevity described by incessant family movement; lack of opportunity and the vicinity of mental elements. Though Venter et al. (2017) had holistic look at how child abuse may cause trauma and multifaceted dysfunctions due to the 'chronic fatigue syndrome', but still they have not attributed the degree of dysfunction with the source of the abuse. So, it would be interesting to observe how the source of the childhood abuse as well as the nature of the abuse in form of physical, emotional or sexual, may have an inter-temporal impact upon compliance with codes of sexual harassment.

Gagné, Marie-H., Lavoie F., \& Hébert M. (2005), using a sample of several students observed that persons with a history of childhood sexual abuse, remain vulnerable and deprived even later, in form of greater the propensity and risk of victimization. The correlation between child abuse and offender is all the more regularly clarified regarding the more predominant and observationally settled viewpoints in criminal hypothesis - social control (or social holding), social learning and social-mental strain hypotheses: Social control hypothesis underscores that solid connection to the family controls or debilitates committing an offense. Subsequently, for the sub-bunch, parental misuse may bring about poor connection, which thus neglects to prevent the youngster from offending. Social learning hypothesis underlines the offender as a scholarly wonder through techniques of demonstrating, impersonation and maybe support. The sub-gathering is said to learn and embrace the examples of conduct showed by their abusers. Though both the gender are prone to risk of harassment, however deprived positionality of females at the workplace and/ or belonging to ethnic/ religious minorities may increase the propensity or the risk of being harassed at the workplace (Berdahl, Magley, \& Waldo, 1996; McGinley et al., 2016; Rosenthal et al., 2016).

Social-mental strain hypothesis accentuates that negative treatment from others (or strain) has a tendency to create negative feelings, for example, annoyance, dissatisfaction and disdain. This makes weights for restorative activity, with the offender being one conceivable reaction. Since every hypothesis distinguishes a vital yet separate part of the relationship between offender and childhood abuse, the model of intercession upheld in this paper makes note of these theories.

\section{Methodology: Questionnaire Design, Data Instruments and Econometric Models}

Keeping in view cross-sectional foundation of the proposed topic, a detailed questionnaire with several sections was floated in the form of personal interview. Each interview took around two hours or more. In order to be able to claim reasonable generalizability of findings, 29 respondents were studied. The forthcoming discussion encompasses methodological details, model estimates and interpretation of findings.

Questionnaire Design: In order to retrieve the data through a structured questionnaire, compliance and noncompliance with codes of harassment are divided into three main categories namely physical, verbal and non-verbal: as suggested by the task force on sexual harassment at the United Nations. Extent or frequency of each kind of harassment is quantified on Likert/ordinal scales from 1 to 5: 1 showing low compliance or high frequency of provocation, while 5 imply high compliance with codes of harassment or absence of provocation. A total of 24 questions were posed for reasonable coverage of all three aspects of sexual harassment, on the basis of which high/low compliance with codes of harassment has been evaluated. Average/composite estimate of these three categories was then taken in order to get the composite value of compliance/non-compliance with codes of Sexual Harassment. Higher the composite value; the more compliant the respondent is with the codes of harassment and the lesser the value is the less compliant he is with the codes.

The questionnaire is designed in a manner that it is divided into number of sections such as on Demographics $\&$ profile of respondents; Organizational Culture and workflow interdependence; Cultural norms and heritage; History of childhood physical abuse; History of the childhood emotional abuse; History of childhood sexual abuse; Peer pressure; Inducement by the victim; compliance/ non compliance with codes of sexual harassment; Opportunity cost of reporting instance(s) of harassment; while series of questions were posed with regards to assessing Personality traits such as Agreeableness, Risk loving/ aversion, Outward/ Inward looking and last but not the least regarding Jealously. In most cases as each analytical aspect has been deeply probed through series of questions, so composite averages are estimated at the end to approximate a series of questions such as in case of peer pressure, history of emotional abuse, induced by the 
victim and in case of personality traits. Conducting a lengthy structured questionnaire that comprised of total 211 questions, took from 2 to 3 hours to each respondent to provide the needed information.

Specification of Competing Econometric Models: Keeping in view semi-parametric or non-parametric orientation of regressand and regressors, extensive use of the ordinal scale has been exercised in the quantification phase. Consequently, two closely related or alternative models namely 'Ordered Logit' and 'Ordered Probit' have been specified, while Robust regression has been proposed keeping in view the apprehension of heteroscedasticity in the cross-sectional data. Estimates of closely related and alternative models have been reported side by side, in accordance with the tradition of within method triangulation, to consolidate findings of models comprehensively: commonly known as concurrent validity. The generic functional form of the model is as follow:

Compliance with Codes of Sexual Harassment $=f$ (Source of childhood emotional abuse, Neighbourhood effect, assault been induced by the victim, Exposure to Physical and Emotional distress, Personality trait: Jealousy).

\section{Model Estimates, Analysis and Discussion}

Estimates of Ordered probit; Robust regression; and Ordered logit have been furnished using Stata. Regressed in all three competing models is the overall (composite) estimate of compliance/noncompliance with codes of sexual harassment, which is based upon series of 24 questions, covering all three types of harassment: 'Physical', 'Verbal', by 'Gesture'. Key regressors include the source of childhood provocation; neighborhood effect that may be witnessed in form of weak/strong peer effect; exposure to physically or the emotionally distressing environment; inducement by the victim; and personality trait: jealousy. Along with each regression coefficient, p-value (the probability of approving the hypothesis that the variable is insignificant $\mathrm{H}_{\mathrm{O}}=0$; and the estimate of $\mathrm{z} / \mathrm{t}$ are given. All three models have highly consistent findings, implying concurrent validity. We tend to believe that high consistency of estimates was strongly backed by the quality of interviewe as well as openness of making a new proposition, at the stage of model specification. In lengthy questionnaires, it is always tricky to specify a model with moderate to high explanatory power. Experimenting composite (aggregated) or highly decomposed variables as part of potential regressors require a lean judgement of researchers. Thoughts and impressions that we experience while conducting questionnaires provide us with a series of likely or the wanted hypotheses, and probably, we can avoid mere experimentation in the urge of estimating a good econometric model, by synchronizing our experiences \& thoughts with experimentation in the model building phase. We also feel that the quality of the questionnaire and representativeness of selected samples have a vital and pivotal role in this regard.

Table 1. Estimates of Ordered-logit, Robust Regression and Ordered-probit Models

\begin{tabular}{|c|c|c|c|}
\hline \multicolumn{4}{|c|}{$\begin{array}{c}\text { Regressand: Composite scale of Compliance with Codes of Sexual Harassment based upon } 24 \text { item scales. } \\
\text { Questions include all } 3 \text { forms of harassment: Physical, Verbal and nonverbal. } \\
\text { Scale: 1-5 (1:Low Compliance with codes, 5:High Compliance) }\end{array}$} \\
\hline Regressors & $\begin{array}{c}\text { Ordered } \\
\text { logitModel }\end{array}$ & $\begin{array}{c}\text { Robust } \\
\text { Regression }\end{array}$ & $\begin{array}{c}\text { Ordered } \\
\text { probitModel }\end{array}$ \\
\hline $\begin{array}{l}\text { Source of Childhood Abuse: Emotional } \\
\text { Scale: 1-5 (1: by Blood relatives, 5: by strangers) }\end{array}$ & $\begin{array}{c}-0.84386 \\
0.08 \\
(-1.75)\end{array}$ & $\begin{array}{c}-.1889285 \\
0.015 \\
(-2.63)\end{array}$ & $\begin{array}{l}-.3067405 \\
0.213 \\
(-1.25)\end{array}$ \\
\hline $\begin{array}{l}\text { Composite estimate of Neighborhood Effect, } \\
\text { Based upon } 6 \text { item scales: } \\
\text { Scale: 1-5: (1: High Peer Pressure,5: Low Peer Pressure) }\end{array}$ & $\begin{array}{c}0.9849 \\
0.011 \\
(2.55)\end{array}$ & $\begin{array}{l}2.388 \\
0.001 \\
(3.74)\end{array}$ & $\begin{array}{c}.461589 \\
0.031 \\
(2.15)\end{array}$ \\
\hline $\begin{array}{l}\text { Composite estimate of 'Induced by the Victim', } \\
\text { Based upon } 9 \text { item scales: } \\
\text { Scale: 1-5: (1: High Inducement, 5: Less Inducement) }\end{array}$ & $\begin{array}{c}2.2455 \\
0.00 \\
(3.67)\end{array}$ & $\begin{array}{c}0.4775 \\
0.000 \\
(6.45)\end{array}$ & $\begin{array}{l}1.247749 \\
0.00 \\
(3.81)\end{array}$ \\
\hline $\begin{array}{l}\text { Exposure to Physical and Emotional Abuse } \\
\text { Scale: 1-5 (1: High Emotional Abuse, 5: Less Emotional Abuse) }\end{array}$ & $\begin{array}{c}2.42744 \\
0.00 \\
(3.98)\end{array}$ & $\begin{array}{l}.455728 \\
0.000 \\
(6.78)\end{array}$ & $\begin{array}{l}1.246858 \\
0.00 \\
(4.00)\end{array}$ \\
\hline $\begin{array}{l}\text { Personality trait: Jealousy } \\
\text { Scale: } 1-5 \text { (1: Low Jealousy, 5: High Jealousy) }\end{array}$ & $\begin{array}{c}-0.9416 \\
0.013 \\
(-2.48)\end{array}$ & $\begin{array}{c}-.20057 \\
0.001 \\
(-3.77)\end{array}$ & $\begin{array}{c}-.4969173 \\
0.013 \\
(-2.48)\end{array}$ \\
\hline Constant & ----- & 1.1157 & $-\cdots$ \\
\hline $\mathrm{N}$ & 29 & 29 & 29 \\
\hline \multicolumn{4}{|l|}{ Estimates of Goodness of Fit and model Consolidation tests: } \\
\hline Pseudo $\mathrm{R}^{2}$ & 0.3179 & ----- & 0.3079 \\
\hline Prob> $\mathrm{Chi}^{2}$ & 0.0000 & 0.0000 & 0.0000 \\
\hline F Ratio & ---- & 45.51 & ----- \\
\hline
\end{tabular}

Note: Below the coefficient, P-value and in ( ) parentheses we report Z/t values

Source: Own elaboration 
ISSN (online) - 2520-6311; ISSN (print) - 2520-6761

Signs of estimates of regression along with significance infer: significant causation in form of high compliance with codes of harassment by persons with history of childhood emotional abuse by blood relatives; strong positive causation between the neighbourhood effect or the peer pressure upon intent of provocation; strong impact of 'induced by victim' in provocation intent; strong positive of 'exposure to physical \& emotional distress'; while a positive correlation of jealously upon indented provocation.

McFadden's pseudo $\mathrm{R}^{2}$ estimate for the Ordered-logit model comes 0.3179, whereas for the Ordered-probit is 0.3079 , with approximate 0 probability of believing that proposed models appear insignificant. The Likelihood ratio of Robust regression 45.51 with approximate 0 percent probability of inferring that the estimated model is insignificantly, entail goodness of fit of the estimated model. The tradition of applied econometric modeling implies that these estimates, especially in cross-sectional setting show moderate to the high explanatory power of all three estimated models. Further, model consolidation tests for heteroscedasticity, using Breusch-Pagan/Cook-Weisberg tests implied low inclination to believe if model estimates and their reliance have been affected adversely due to apprehension of heteroscedasticity.

\section{Conclusion}

Sexual harassment is a communal problem which necessities to be tended as a genuine need along with fitting measures. Instruments for the avoidance of sexual provocation along with security of women requires working in all aspects: stringent initiatives and operationalization of low/high intensity of harassment/provocation is needed by legislatures in recognizing the complexity of the issue and in developing better operational definitions of violation of codes of harassment; strong political willingness is needed by businesses \& corporations in providing protection to the vulnerable and to think how the high opportunity cost which is being paid by the victim may be reduced; and last but not the least, representatives of female associations and the civil society, in particular, require a persistent pressure to build in forms of continual follow-up. Aversion, resentment and creating resilience are amongst influential instruments for annulment of harassment, which could likewise be accomplished via free attention to people. Moreover, executive associations and government should implement suitable ways to rationalize the arrangements and usage.

Civil society and organizations meant for rehabilitation of offenders, require an in-depth understanding of the issues, should arrange awareness literature/ complains, while associations of lawyers should provide advocacy services, free of cost to victims. We believe that steps such as termination of the job of offender etc. would probably delay the crime for spreading but to create resilience, offenders require more emphasis on psychological treatment/psychotherapy, etc.

\section{Acknowledgment}

Authors greatly admire contribution by Nadeem Syed, Kristen Nordhaug and by Saima Toqueer for their untiring support, valuable suggestions and critical comments on manuscript. We are also indebted to participants of the survey: who trusted us in sharing sensitive information and spent sizable time in responding to a lengthy questionnaire.

\section{References}

1. Abbey, A., McAuslan, P., \& Ross, L.T. (1998). Sexual assault perpetration by college men: The role of alcohol, misperception of sexual intent, and sexual beliefs and experiences. Journal of Social and Clinical Psychology, 17(2), 167-195. E-ISSN: 19432771.

2. Abracen, J., Looman J., \& Anderson D. (2000). Alcohol and drug abuse in sexual and nonsexual violent offenders. Sexual Abuse. A Journal of Research and Treatment, 12(4), $263-274$. DOI:10.1023/A:1009538526846.

3. Amir-Ud-Din, R., Fatima, S., \& Aziz, S. (2018). Is Attitudinal Acceptance of Violence a Risk Factor? An Analysis of Domestic Violence against Women in Pakistan. Journal of interpersonal violence, DOI:10.1177/0886260518787809.

4. Berdahl, J. L., Magley, V. J., \& Waldo, C. R. (1996). The sexual harassment of men? Exploring the concept with theory and data. Psychology of Women Quarterly, 20, 527-547. DOI: 10.1111/j.14716402.1996.tb00320.x.

5. Boland, F. J., Henderson, K., \& Baker, J. (1998). Case needs review: Substance abuse domain. Forum of Correction Research. Addictions Research Centre, Correctional Service of Canada (R-76). 
6. Briere, J., \& Runtz, Marsha (1987). Post Sexual Abuse Trauma: Data and Implications for Clinical Practice. Journal of Interpersonal Violence, 2(4), 367-379. DOI: 10.1177/088626058700200403.

7. Channar, Zahid A., Abbassi, Z., \& Ujan, Imran A. (2011). Gender discrimination in workforce and its impact on the employees. Pakistan Journal of Commerce and Social Sciences, 5(1), 177-191. ISSN: 1997-855.

8. Clancy, Kathryn B. H., Robin, G. Nelson, Julienne, N. Rutherford, and Katie, Hinde (2014). Survey of Academic Field Experiences (SAFE): Trainees Report Harassment and Assault. PLOS ONE 9 (7). DOI:10.1371/journal.pone.0102172.

9. Critelli, F. M. (2010). Women's rights and Human rights: Pakistani women against gender violence. Journal of Sociology and Social Welfare, 37, 135-160. ISSN: 0191-5096.

10.Cullingford, C. \& Morrison, J. (1997). The Relationship between Criminality and Home Background. Children and Society, 11, 157-172. DOI: 10.1111/j.1099-0860.1997.tb00023.x.

11.Erik, Bihagen \& Marita, Ohls (2006). The Glass ceiling-where is it? Women's and men's career prospects in the private vs. the public sector in Sweden 1979-2000. The Sociological Review, 54(1), 20-47. DOI:10.1111/j.1467-954X.2006.00600.x.

12.Fian T. C., \& Anderton, D. L. (1987). Sexual harassment: Organizational context and diffuse status. Sex Roles, 13, 291-311. DOI: 10.1007/BF00288454.

13.Fitzgerald, Louise F., et al. (1988). The incidence and dimensions of sexual harassment in academia and the workplace. Journal of vocational behaviour, 32(2), 152-175. DOI: 10.1016/0001-8791(88)90012-7.

14.Gagné, Marie-H., Lavoie F., \& Hébert M. (2005). Victimization during childhood and revictimization in dating relationships in adolescent girls. Child Abuse \& Neglect, 29(10), 1155-1172. DOI:10.1016/j.chiabu.2004.11.009.

15.Gutek, B.A., \& Morasch, B. (1982). Sex-ratios, sex-role spill-over, and sexual harassment of women at work. Journal of Social Issues, 38, 55-74. https://doi.org/10.1111/j.1540-4560.1982.tb01910.x.

16.Gutek, B.A., Cohen, A.G., \& Konrad A.M. (1990). Predicting social-sexual behaviour at work: a contact hypothesis. Academy of Management Journal, 33, 560-577. ISSN: 0001-4273.

17.Hamlin, L., \& Hoffman, A. (2002). Preoperative nurses and sexual harassment. AORN J, 76(5), 855-60. DOI: 10.1016/S0001-2092(06)61039-9.

18.Hemming, H. (1985). Women in man's world: sexual harassment. Human Relations, 38, 67-79. DOI: $10.1177 / 001872678503800104$.

19.Langevin, R., \& Lang, R. A. (1990). Substance abuse among sex offenders. Annals of Sex Research, 3(4), 397-424. DOI: $10.1007 / \mathrm{BF} 00850442$.

20.Mahmood, Q. K., \& Ahmad, I. (2011). Perception of sexual Harassment at workplace, Knowledge and attitude of working women towards workplace Harassment Act 2010. Social Sciences Review of Pakistan, 22.

21.Marshall, W. L., Bryce Peter S., Hudson, T. M. \& Moth, Ward B. (1996). The enhancement of intimacy and the reduction of loneliness among child molesters. Journal of Family Violence, 11(3), 219-235. DOI:10.1007/BF02336942.

22.McGinley, M., Wolff, J. M., Rospenda, K. M., Liu, L., \& Richman, J. A. (2016). Risk factors and outcomes of chronic sexual harassment during the transition to college: Examination of a two-part growth mixture model. Social Science Research, 60, 297-310. DOI: 10.1016/j.ssresearch.2016.04.002.

23.McGue, M., Slutske, W., \& Iacono, W. G. (1999). Personality and substance use disorders: II. Alcoholism versus drug use disorders. Journal of Consulting and Clinical Psychology, 67(3), 394-404. DOI: 10.1037/0022-006X.67.3.394.

24.Naveed, A., Tharani, A., \& Alwani, N. (2010). Sexual harassment at work place: Are you safe? Journal of Ayub Medical College, 22(3), 222-224. ISSN: 1025-9589.

25.Olson, Craig A., and Brian E. Becker (1983). Sex discrimination in the promotion process. Industrial and Labour Relations Review, 36(4), 624-41. E-ISSN: 2162271X.

26.Pakistan Bureau of Statistics (2017). Household Integrated Economic Survey (HIES) 2015-16. Pakistan Bureau of Statistics, Statistics Division, Government of Pakistan.

27.Parveen, R. (2010). Violence against Women in Pakistan. Islamabad: Aurat Foundation. The Protection against Harassment of Women at the Workplace Act 2010. [Accessed on 09 July, 2019].

28.Qureshi, M. B., Qureshi, S. B., Taherani, A., \& Ansari, S. (2012). Coping with sexual harassment: the experiences of junior female student nurses and senior female nursing managers in Sindh Pakistan. The Women: Annual Research Journal, 4, 65-80.

29.Richman, J. A., Rospenda, K. M., Flaherty, J. A., \& Freels, S. (2001). Workplace harassment, active coping, and alcohol-related outcomes. Journal of Substance Abuse, 13(3), 347-66. DOI: 10.1016/S08993289(01)00079-7. 
30.Richman, J. A., Rospenda, K. M., Nawyn, S. J., Flaherty, J. A., Fendrich, M., Drum, M. L., \& Johnson, T.P. (1999). Sexual harassment and generalized workplace abuse among university employees: prevalence and mental health correlates. American Journal of Public Health, 89(3), 358-363. ISSN: 00900036.

31.Ridgeway, C., \& England, P. (2007). Sociological Approaches to Sex Discrimination in Employment. In F. J. Crosby, M. S. Stockdale, \& S. Ann Ropp (Eds.), Sex Discrimination in the Workplace Oxford: Blackwell.

32.Rosenthal, M. N., Smidt, A. M., \& Freyd, J. J. (2016). Still second class: Sexual harassment of graduate students. Psychology of Women Quarterly, 40(3), 364-377. DOI: 10.1177/0361684316644838.

33.Sangwan, D., \& Thakre, A. (2018). Sexual harassment at the workplace in public and private sectors in India: A study at National Capital Region of Delhi. International Journal of Criminal Justice Sciences, 13(1), 29-43. DOI: 10.5281/zenodo.1403380.

34.Shaikh, M. A. (2016). Domestic violence in consanguineous marriages - Findings from Pakistan Demographic and Health Survey 2012-13. JPMA: The Journal of the Pakistan Medical Association, 66, 1319-1323. ISSN: 0030-9982.

35.Venter, Maud D., Illegems, J., Royen, Rita V., Moorkens, G., Sabbe, Bernard G.C., \& Eede, Filip V. D. (2017). Differential effects of childhood trauma subtypes on fatigue and physical functioning in chronic fatigue syndrome. Comprehensive Psychiatry, 78, 76-82. DOI: 10.1016/j.comppsych.2018.12.011.

36.World Economic forum (2018). Global Gender gap Report, 2018. Published by World Economic forum.

37.Zakar, R., Zakar, M. Z., Kraemer, A. (2013). Men's Beliefs and Attitudes Toward Intimate Partner Violence Against Women in Pakistan. Violence against Women, 19(2), $246-268$. DOI: $10.1177 / 1077801213478028$. 